\title{
TINJAUAN KAPASITAS ABUTMEN JEMBATAN SENGKALING MALANG DENGAN BEBAN GEMPA
}

\author{
Nindi Rizki Apriliani', Pujo Priyono², Arief Alihudien². \\ Program Studi Teknik Sipil, Fakultas Teknik, \\ Universitas Muhammadiyah Jember Jl. Karimata 49, Jember 68121, Indonesia \\ Email : nindirizki68@gmail.com
}

\begin{abstract}
The bridge is a construction that's the point of continue on the path through the obstacles that are lower. This obstacle is usually another way such as roads water or ordinary traffic. On planning and bridge work Planning the Structure of the Bottom can not be ignored.Part of the bridge structure is located at the bottom of very decisive for the strength and security of the building thereon.And for a direct link between the structure of the bridge structure under the bridge is the "Abutment" which is included on the structure under the bridge.Abutments of a building that serves to continue the load.Loading code that is used to plan bridge this refers to Indonesian National Standard SNI 1725:2016.The intensity of the earthquake is greatly increased, cause a change in the planning of bridges, the changes contained in the regulation SNI 2833:2016 about planning for earthquake resistance of the bridge. Bridge Sengkaling is a bridge alternative to ease the traffic toward Sengkaling Recreational Park located in Malang, East Java. With a length of $28 \mathrm{~m}$ and $a$ width of $10 \mathrm{~m}$ this is behind the University of Muhammadiyah Malang.
\end{abstract}

Keywords :Abutment,Earthquake Loads, Of The Bridge, Sengkaling Recreation Park, The UniversityOf Muhammadiyah Malang. 


\section{PENDAHULUAN}

Jembatan merupakan sebuah struktur penting yang dibuat untuk menyeberangi suatu rintangan seperti jurang, sungai, rel kereta api, ataupun jalan raya.Jembatan juga merupakan bagian dari infrastruktur transportasi darat yang sangat fital dalam aliran suatu perjalanan atau lalulintas, karena sebagai penghubung antar daerah untuk menunjang perkembangan ekonomi, sosial, budaya, dan pariwisata suatu daerah.

Suatu jembatan terdiri atas bagian bawah dan bagian atas.Bagian bawah memikul atau mendukung bagian atas jembatan dan meneruskan beban bagian atas beserta beban lalu lintasnya kepada dasar tanah.Bagian bawah juga terdiri atas tembok-tembok penahan, abutmen, pilarpilar, dan juga pondasi. Akibat beban berulang, cuaca, maupun beban yang bertambah seiring perkembangan transportasi antar daerah akan mengakibatkan penurunan daya dukung jembatan.

Maka dari itu adanya perencanaan ulang ataupun tinjauan ulang sangat diperlukan guna mendukung beban yang melintas pada jembatan agar jembatan tetap stabil dalam menerima beban.Karenanya sangat pentingnya, maka jembatan harus dibuat cukup kuat.Agar tidak menimbulkan gangguan terhadap kelacaran lalu-lintas sendiri, terlebih di jalan yang memang padat lalu-lintasnya. Jembatan segkaling merupakan jembatan yang berada di Malang Jawa Timur. Jembbatan ini dibuat untuk jalur alternatif menujutempat wisata tersebut. Dengan semakin banyaknya minat masyarakat mengunjungi salah satu tempat wisata ini, sangat memungkinkan terjadi kemacetan, maka dari itu direncanakan sebuah jembatan penghubung kelancaran lalu lintas, sebelum jembatan ini terealisasi, maka di rencanakan dari segala sapek bangunan, kekuatan,hingga pengaruh terhadap gaya gempa itu sendiri.Dengan lebar jembatan $10 \mathrm{~m}$ dan panjang 28
meter.Menggunakan peraturan SNI 2833:2016 mengenai perencanaan jembatan terhadap beban gempa dan SNI 1725:2016 tentang pembebanan untuk jembatan.

\section{METODE}

\section{Struktur konstruksi jembatan}

Secara umum konstruksi jembatan memiliki dua bagian yaitu bangunan atas (upper structure), bangunan bawah (sub structure), dan pondasi. Bangunan atas adalah konstruksi yang berhubungan langsung dengan beban-beban lalu lintas yang bekerja.Sedangkan bangunan bawah adalah konstruksi yang menerima bebanbeban dari bangunan atas dan meneruskannya ke lapisan pendukung (tanah keras) di bawahnya. Dan pondasi yang meneruskan beban menyebar ke tanah.

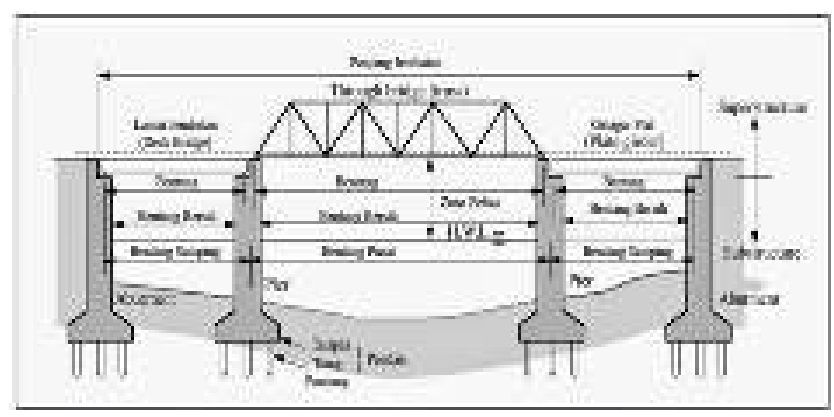

Gambar 2.1 Bagian-bagian konstruksi jembatan

Sumber: Chen and Duan, 2000

1. Bangunan atas Jembatan

Bangunan atas terletak pada bagian atas konstruksi jembatan yang menampung beban-beban lalu lintas, orang, barang dan berat sendiri konstruksi yang kemudian menyalurkan beban tersebut ke bagian bawah. Bagian-bagian bangunan atas suatu jembatan terdiri dari:

a. Sandaran

Berfungsi untuk membatasi lebar dari suatu jembatan agar membuat rasa aman bagi lalu lintas kendaraan maupun orang yang melewatinya.

b. Rangka Jembatan

Rangka jembatan terbuat dari 
baja profil seperti tipe WF, sehingga lebih baik dalam menerima beban-beban yang bekerja secara lateral

c. Trotoar

Merupakan tempat pejalan kaki yang terbuat dari beton, bentuknya lebih tinggi dari lantai jalan atau permukaan aspal.

d. Lantai kendaraan

Merupakan lintasan utama yang dilalui kendaraan, lebar jalur kendaraan yang diperkirakan cukup untuk berpapasan.

e. Gelagar Melintang

Berfungsi menerima beban lantai kendaraan, trotoar dan beban lainnya

f. Ikatan Angin atas/bawah dan Ikatan rem

Ikatan angin berfungsi untuk menahan atau melawan gaya yang diakibatkan oleh angin,

g. Landasan/perletakan

Landasan atau perletakan dibuat untuk menerima gaya-gaya dari konstruksi bangunan atas baik secara horizontal, vertikal maupun lataeral.

2. Bangunan Bawah Jembatan

Bangunan ini terletak pada bagian bawah konstruksi yang fungsinya untuk memikul beban-beban yang diberikan bangunan atas, kemudian disalurkan ke pondasi dan dari pondasi diteruskan ke tanah keras di bawahnya.

\section{a. Abutment}

Abutment atau kepala jembatan adalah salah satu bagian konstruksi jembatan yang terdapat pada ujungujung jembatan

b. Pilar (Pier)

Pilar adalah suatu bangunan bawah yang terletak di tengah-tengah bentang antara dua buah abutment yang berfungsi juga untuk memikul bebanbeban

c. Pondasi

Pondasi berfungsi untuk memikul beban di atas dan meneruskannya ke lapisan tanah

d. Plat Injak

Pelat injak berfungsi untuk menahan hentakan pertama roda kendaraan ketika akan memasuki awal jembatan.

\section{Bagian-bagian Abutmen}

a. Pelat Dasar/Tumpuan (Pile Cape) Pelat Dasar/tumpuan (Pile Cap) yang terdiri dari tumpuan muka dan tumpuan belakang,

b. Dinding (Breast Wall)

Dinding (Breast Wall) yang disebut juga tembok longitudinal, dimana kontruksi ini harus mampu menerima gaya-gaya yang ada pada jembatan.

c. Tempat Sepatu

Merupakan konstruksi tempat perletakan dari gelagar memanjang maupun melintang.

d. Perletakan

Perletakan, merupakan bantalan yang berfungsi untuk mengurangi getaran yang terjadi pada gelagar akibat beban dan kendaraan yangbergerak.

e. Back Wall

Back wall merupakan kontruksi dinding yang berfungsi sebagai pembatas antara gelagar dengan tanah belakang abutmen.

f. Wing Wall

Wing wall berfunsi untuk melindungi bagian belakang abutment dari tekanan tanah yang bekerja. 


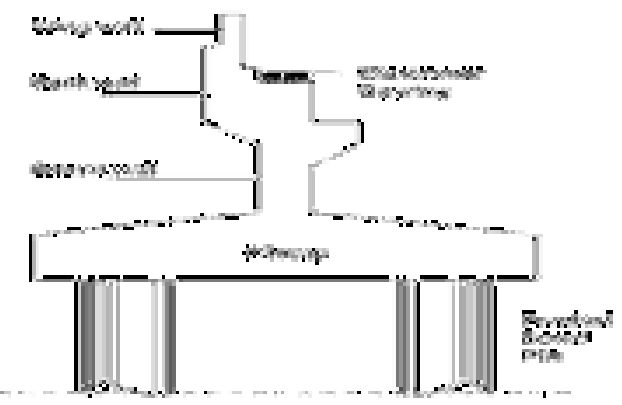

Gambar 2.2 Bagian - Bagian Abutmen

Sumber: Chen and Duan, 2000

\section{Standart Perhitungan Konstruksi Jembatan}

Adapunacuanyang

penulisgunakandalamlaporaniniadala hsebagai berikut:

$\begin{array}{lr}\text { - SNI 1725:2016 } & \text { Standar } \\ \text { Pembebanan } \\ \text { Jembatan } \\ \text { - SNI 2833:2016 } & \text { Standar } \\ \text { Perencanaan Gempa } & \text { untuk } \\ \text { Jembatan. } & \end{array}$

\section{Standart Pembebanan Jembatan}

Berdasarkan SNI 1725-2016tentang Standar Pembebanan Untuk Jembatan, beban padajembatan terbagiatas:

Aksi Beban Tetap

- Beban Sendiriberat dari bagian tersebut dan Beban T Pembebanan truk"T"terdiri darikendaraantruk semi-traileryang

mempunyaisusunandan berates

Beratdarimasing-

masingasdisebarkan elemen-elemen struktural lain yang dipikulkan. Termasuk dalam hal ini adalah berat bahan dan bagian jembatan yang merupakan elemen struktural, ditambah dengan elemen nonstruktural yang dianggap tetap.

- Bebanmatitambahanadalahberatselur uhbahanyang membentuksuatu bebanpadajembatanyang merupakanelemen nonstruktural,danbesarnya dapat berubah selama umurjembatan.

- Tekanan Tanah

Koefisientekanantanahnominalharus dihitungberdasarkansifat-sifattanah, harus diperolehberdasarkan hasilpengukurandanpengujiantanahb aikdilapanganataupun laboratorium.

Beban Lalu Lintas

- Beban D Bebanlajur "D" terdiridaribebantransfermerata (BTR)yang digabungkandenganbebangaristerpus at (BGT) menjadi 2 beban merata sama besar yang merupakan bidang kontak antara rodadengan permukaan lantai.

- Gaya Rem Bekerjanyagayagayakearahmemanjang jembatan,akibatgayaremdan traksiharus ditinjauuntukkedua jurusanlalulintas.

- Beban Angin Gaya nominalultimitdandaya layanjembatanakibatangintergantung kecepatan angin rencana.

- Beban Gempa Pasal ini menetapkan metode untuk menghitung beban statis ekuivalen untukjembatan dimana analisa statisekuivalenadalah sesuai

untukjembatanbesar,rumitdanpenting mungkindiperlukananalisa dinamis

- Gaya Akibat perletakan pada gesekan Gesekan pada perletakan termasuk pengaruh kekakuan geser dari perletakan elastomer.

\section{Perhitungan Struktur Bawah}

Perhitungan bangunanjembatan bagian bawah meliputi abutment, plat injak, pondasi.

1. Perhitungan Abutment Pembebanan yang terjadi pada abutment:

- Berat sendiri abutmen

- Akibat beban hidup

- Akibat tekanan tanah aktif

- Beban angin

- Gaya rem 
- Gaya gempa

- Gesekan pada perletakan

- Beban pelaksanaan

Kombinasi pembebanan abutment:

- Daya Layan 1

- Daya Layan 2

- Daya Layan 3

- Daya Layan 4

- Ekstrim 1

2. Analisis Beban Kerja Pada Abutment:

- Berat Sendiri Struktur atas (MS)

$\mathrm{P}_{\mathrm{MS}}=\frac{1}{2} \times \mathrm{W}_{\mathrm{MS}}$

- Beban mati tambahan (MA)

$\mathrm{P}_{\mathrm{MA}}=\frac{1}{2} \mathrm{~W}_{\mathrm{MA}}$

- Tekanan Tanah (TA)

$\varphi^{\prime}=\tan -1\left(\mathrm{~K} \varphi \mathrm{R}^{*} \tan \varphi\right)(2.3)$

$\mathrm{Ka}=\tan 2\left(45^{\circ}-\varphi^{\prime} / 2\right)$

- Beban Lajur "D"

$\mathrm{WTD}=\mathrm{q} \times \mathrm{L} \times \frac{(5.5+b)}{2}+\mathrm{p} \times$ DLA $\mathrm{x} \frac{(5.5+b)}{2}$

$\mathrm{PTD}=\frac{1}{2} \mathrm{WTD}$

- Beban Pedestrian/pejalan kaki (TP)

$\mathrm{P}_{\mathrm{TP}}=\mathrm{A} \times \mathrm{q}$

- Gaya rem

TTB $=n *$ TTB

- Pengaruh Temperatur

$\Delta \mathrm{T}=(\mathrm{T} \max -\mathrm{T} \min ) / 2$..(2.9)

$\mathrm{TET}=\alpha * \Delta \mathrm{T} * \mathrm{k} * \mathrm{~L} / 2 *$ n..(2.10)

- Beban Angin

$\mathrm{TEW} 1=0.0006 * \mathrm{Cw} *(\mathrm{Vw}) 2 * \mathrm{Ab}$ ....(2.11)

TEW $2=0.0012 * \mathrm{Cw}^{*}(\mathrm{Vw})^{2} * \mathrm{~L} / 2$ ...(2.12)

$\mathrm{P}_{\mathrm{EW}}=2 \times\left(0.5 \times \frac{h}{x} \mathrm{x} T_{E W}\right) \times\left(\frac{L}{2}\right)(2.13)$

- Beban Gempa $\mathrm{TEQ}=\mathrm{Kh} * \mathrm{I} * \mathrm{Wt}$

$\mathrm{T}=2 * \pi * \sqrt{ }[\mathrm{WTP} /(\mathrm{g} * \mathrm{KP})]$ ..(2.15)

$\mathrm{Kh}=\mathrm{C} * \mathrm{~S}$ (2.16)

$\mathrm{Csm}=(\mathrm{SDS}-\mathrm{AS}) \mathrm{T} / \mathrm{To}+\mathrm{A}_{\mathrm{S}} \ldots \ldots$ (2.17)

Gesekan Pada Perletakan
TFB $=$

\author{
$\mu$
}

3. Perhitungan Stabilitas Abutment

- Kontrol Stabilitas Guling arah x $\mathrm{Mpx}=\mathrm{P} *(\mathrm{Bx} / 2) *(1+\mathrm{k})$ ......(2.19)

$\mathrm{SF}=\mathrm{Mpx} / \mathrm{Mx}$ harus $\geq 2.2$ ......(2.20)

Mpy $=\mathrm{P} *(\mathrm{By} / 2) *(1+\mathrm{k}) \ldots .$. .(2.21)

$\mathrm{SF}=$ Mpy / My harus $\geq$ $2.2 \ldots \ldots . .(2.22)$

- Kontrol Stabilitas Geser

$\mathrm{H}=(\mathrm{C} * \mathrm{Bx} * \mathrm{By}+\mathrm{P} * \tan \varphi)^{*} \quad(1+\mathrm{k} \quad) \ldots$ (2.23)

$\mathrm{H}=(\mathrm{C} * \mathrm{Bx} * \mathrm{By}+\mathrm{P} * \tan \varphi) *(1+\mathrm{k}) \mathrm{hrs} \geq$ 1,1

\section{HASIL DAN PEMBAHASAN}

Pada penelitian ini membahas tentang kapasitas abutmen dengan beban gempa pada jembatan Taman Rekreasi Sengkaling Malang.Struktur abutmen yang memenuhi segi keamanan dan ekonomis merupakan suatu hal yang sangat penting. Oleh karena itu dibutuhkan analisis mengenai abutmen jembatan dengan perhitungan analisis yang tepat guna mendapatkan hasil perencanaan yang maksimal.

Berikut peraturan yang digunakan adalah:

a. SNI 1725:2016 (Pembebanan untuk jembatan)

b. SNI 2833:2016 (Perencanaan Beban Gempa pada Jembatan)

1. Data Struktur Atas

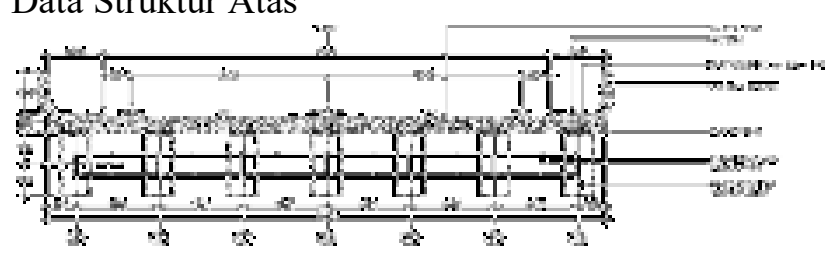

Gambar 3.1 Potongan Melintang

Jembatan

Sumber: Data Proyek 
Tabel 3.1 Uraian Dimensi Jembatan

\begin{tabular}{|c|c|c|c|}
\hline $\begin{array}{l}\text { Uraian } \\
\text { Dimensi }\end{array}$ & Notasi & (m) & Satuan \\
\hline $\begin{array}{ll}\text { Tebal } & \text { slab } \\
\text { lantai } & \end{array}$ & & & \\
\hline $\begin{array}{l}\text { jembatan } \\
\text { tebal aspal }\end{array}$ & $t_{s}=$ & 0,20 & M \\
\hline +overlay & $\mathrm{t}_{\mathrm{a}}=$ & 0,10 & M \\
\hline Tebal lantai & & & \\
\hline $\begin{array}{l}\text { trotoar } \\
\text { tebal }\end{array}$ & $\mathrm{t}_{\mathrm{t}}=$ & 0,20 & M \\
\hline $\begin{array}{l}\text { genangan air } \\
\text { hujan } \\
\text { jumlah balok }\end{array}$ & $t_{h}=$ & 0,05 & M \\
\hline $\begin{array}{l}\text { utama } \\
\text { jarak antara }\end{array}$ & $n=$ & 7 & Buah \\
\hline $\begin{array}{l}\text { balok utama } \\
\text { lebar jalur lalu }\end{array}$ & $\mathrm{s}=$ & 1,50 & M \\
\hline lintas & $b_{1}=$ & 8,00 & M \\
\hline $\begin{array}{l}\text { lebar trotoar } \\
\text { lebar median } \\
\text { (pemisah }\end{array}$ & $\mathrm{b}_{2}=$ & 1,00 & M \\
\hline jalur) & $b_{3}=$ & 0,00 & M \\
\hline $\begin{array}{l}\text { jembatan } \\
\text { panjang } \\
\text { bentang }\end{array}$ & $b=$ & 10,00 & M \\
\hline $\begin{array}{l}\text { jembatan } \\
\text { tinggi girder }\end{array}$ & $\mathrm{L}=$ & 28,00 & M \\
\hline $\begin{array}{l}\text { plat baja } \\
\text { tinggi bidang } \\
\text { samping } \\
\text { jembatan }\end{array}$ & $h_{b}=$ & 1,50 & M \\
\hline
\end{tabular}

Tabel 3.2 Bahan Struktur Jembatan

\begin{tabular}{lll}
\hline Bahan Struktur & Notasi & $(\mathrm{m})$ \\
\hline $\begin{array}{l}\text { Mutu beton } \\
\text { Kuat tekan beton }\end{array}$ & $\mathrm{K}-$ & 300 \\
$\begin{array}{l}\text { Modulus } \\
\text { elastisitas }\end{array}$ & $\mathrm{Ec}=$ & 25742,96 \\
$\begin{array}{l}\text { Angka poison } \\
\begin{array}{l}\text { Modulus geser } \\
\text { Koefisien muai } \\
\text { panjang }\end{array}\end{array}$ & $\mathrm{G}=$ & 0,2 \\
\hline
\end{tabular}

Tabel 3.3 Muju Baja

\begin{tabular}{llll}
\hline Mutu Baja & Notasi & (m) & Satuan \\
\hline $\begin{array}{l}\text { untuk baja tulangan } \\
\text { dengan } \mathrm{d}>12 \mathrm{~mm} \text {, U-39 }\end{array}$ & & 390 & Mpa
\end{tabular}

Tegangan leleh baja, untuk baja tulangan fy $=240 \quad$ Mpa dengan $\mathrm{d}<12 \mathrm{~mm}, \mathrm{U}-24$

Tegangan leleh baja,

Tabel 3.4 Spesi Gravity

\begin{tabular}{llll}
\hline Spesi Gravity & Notasi & $(\mathrm{m})$ & Satuan \\
& & & \\
\hline Berat beton prategang & $\mathrm{W}_{\mathrm{c}}=$ & 25,0 & $\mathrm{kN} / \mathrm{m} 3$ \\
Berat beton bertulang & $\mathrm{W}_{\mathrm{c}}=$ & 24,0 & $\mathrm{kN} / \mathrm{m} 3$ \\
Berat aspal & $\mathrm{W}_{\mathrm{a}}=$ & 22,0 & $\mathrm{kN} / \mathrm{m} 3$ \\
Barat jenis air & $\mathrm{W}_{\mathrm{w}}=$ & 10,0 & $\mathrm{kN} / \mathrm{m} 3$ \\
Berat baja & $\mathrm{W}_{\mathrm{st}}=$ & 77,0 & $\mathrm{kN} / \mathrm{m} 3$ \\
\hline
\end{tabular}

2. Data Struktur Bawah

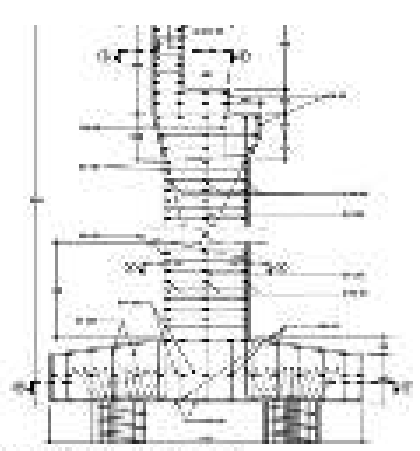

Gambar 3.2 Abulmen

Sumber: Data Struktur proyek

Tabel 3.4 Data Struktur Bawah

\begin{tabular}{|c|c|c|c|c|c|c|}
\hline$w$ & i.) & 4.971 .9 & ix & KFTERARTH & V:T... & for \\
\hline E- & 3,4 & $k_{1}=$ & 625 & furie:azanx: & $\Delta, x$ & $23 x$. \\
\hline $\mathrm{L}=$ & ig & $k-\infty$ & 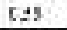 & Atarye:vad & $\mathrm{a}=$ & 62 \\
\hline Ep & 23 & $k,=$ & 125 & \multicolumn{3}{|c|}{ DASAH UMELMAX } \\
\hline $\mathrm{bg}^{*}$ & $t$ & D & & Bers:ab:as:sen= & $\gamma / \boldsymbol{F}$ & 27,2 then \\
\hline te & 13 & $k=$ & {$[\leqslant 5$} & Sda a si:k, & 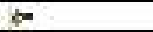 & $\partial^{7}$ \\
\hline$t ;$ & 23 & & & Katcil:= & 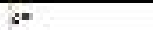 & 3 \\
\hline 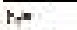 & 255 & $\mathrm{r}_{1}=$ & נI & & \multicolumn{2}{|c|}{ 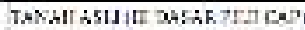 } \\
\hline ise & 135 & $t=$ & $2 \times 1$ & forvatiesoum & $\sigma_{i}$ & $11 \mathrm{k}$.ral \\
\hline$b^{2}$ & 3.35 & $1+\infty$ & $2 x]$ & Fadajul & 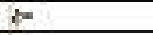 & $13^{\circ}$ \\
\hline re & +1 & $1+\infty$ & (i) & Rrui.j= & $x=$ & $\sin$ \\
\hline 1 & 1 & & & \multicolumn{3}{|c|}{ 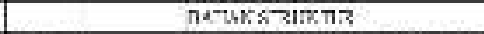 } \\
\hline 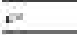 & 127 & $\pi=$ & 3,11 & Wrichess & 7 & $3: 1.410$ \\
\hline c. & 25 & & & 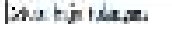 & b & 25 \\
\hline
\end{tabular}

3. Analisis Beban Keja

- Berat Sendiri Struktur Atas

Beban pada abutemen akibat berat sendiri struktur atas,

$\mathrm{P}_{\mathrm{MS}}=\frac{1}{2} \times \mathrm{W}_{\mathrm{MS}}=1466,5 \mathrm{kN}$

Eksentrisitas beban terhadap pondasi, 
$\mathrm{e}=-\frac{B_{x}}{2}+\mathrm{b}_{8}+\frac{b_{7}}{2}=0,15 \mathrm{~m}$

Momen pada pondasi akibat berat sendiri struktur atas,

$\mathrm{M}_{\mathrm{MS}}=\mathrm{P}_{\mathrm{MS}} \mathrm{x}$ e $=219,975 \mathrm{kNm}$

- Berat sendiri Struktur Bawah

Berat Beton $w c=24 \mathrm{kN} / \mathrm{m}^{3}$

Berat Tanah Timbunan $\mathrm{ws}=17,2 \mathrm{kN} / \mathrm{m}^{3}$

Lebar By $=13,0 \mathrm{~m}$

$2 \mathrm{x}$ tebal wingwall $=1,0 \mathrm{~m}$

b12 $=0,85 \mathrm{~m}$

$\mathrm{b} 13=0,65 \mathrm{~m}$

$\mathrm{h} 13=4,6 \mathrm{~m}$

$\mathrm{H}=9,72 \mathrm{~m}$

- Beban Mati Tambahan

Beban pada abutmen akibat beban mati tambahan,

$\mathrm{P}_{\mathrm{MA}}=\frac{1}{2} \mathrm{~W}_{\mathrm{MA}}=579,60 \mathrm{kN}$

Eksentrisitas beban terhadap pondasi, $\mathrm{e}=-\frac{B_{x}}{2}+\mathrm{b}_{8}+\frac{b_{7}}{2}=0,15 \mathrm{~m}$

Momen pada pondasi akibat berat sendiri struktur atas,

$\mathrm{MMA}=$ PMA x e = 86,94 kN-m

- Tekanan tanah lateral dihitung berdasarkan herga nominal dari berat tanah (ws). Sudut gesek dalam $(\varphi)$, dan kohesi c dengan :

$\mathrm{Ws}^{\prime}=\mathrm{Ws}$

$\varphi^{\prime}=\tan ^{-1}\left(K_{\phi} \times\right.$ tan $\left.\phi\right)$ dengan faktor reduksi untuk $\varphi \mathrm{K} \varphi=0,7$

$\mathrm{c}^{\prime}=\mathrm{Kc} \times \mathrm{c}$ dengan faktor reduksi untuk $\mathrm{c}^{\prime}$ $\mathrm{Kc} \mathrm{c}^{\prime}=1$

Koifisien tekanan tanah aktif

$$
\mathrm{Ka}=\tan ^{2}\left(45^{\circ}-\varphi^{\prime} / 2\right)
$$

Berat tanah $\quad \mathrm{Ws}=17,2 \mathrm{kN} / \mathrm{m} 3$

Sudut gesek dalam $\varphi=20^{\circ}$

Kohesi $\mathrm{c}=0 \mathrm{kPa}$

Tinggi total abutment $\mathrm{H}=9,72 \mathrm{~m}$

Lebar abutment $\quad$ By $=13 \mathrm{~m}$

Beban merata akibat berat timbunan tanah setinggi $0,6 \mathrm{~m}$ yang merupakan ekivalen beban kendaraan :

$0,6 \times \mathrm{Ws}=10,32 \mathrm{kPa}$

$\varphi^{\prime}=\tan -1(\mathrm{~K} \varphi \mathrm{R} * \tan \varphi)=1,000250 \mathrm{rad}=$ $57,4387^{\circ}$

$\mathrm{Ka}=\tan 2\left(45^{\circ}-\varphi^{\prime} / 2\right)=0,085343$

- Beban Lajur D

Untuk harga, $\mathrm{L}=28.00 \mathrm{~m} \quad \mathrm{~b} 1=8.00 \mathrm{~m}$ DLA $=0.4$

Besar beban lajur "D" :
$\mathrm{WTD}=\mathrm{q} \times \mathrm{L} \times \frac{(5.5+b)}{2}+\mathrm{p} \times \operatorname{DLAx} \frac{(5.5+b)}{2}=$ $1825,2 \mathrm{kN}$

Beban pada Abutmen akibat beban lajur "D"

$\mathrm{PTD}=\frac{1}{2} \mathrm{WTD}=912,6 \mathrm{kN}$

Eksentrisitas beban terhadap pondasi,

$\mathrm{e}=-\frac{B_{x}}{2}+\mathrm{b}_{8}+\frac{b_{7}}{2}=0,15 \mathrm{~m}$

Momen pada pondasi akibat beban lajur "D"

$\mathrm{M}_{\mathrm{TD}}=\mathrm{P}_{\mathrm{TD}} \times \mathrm{e}=136,89 \mathrm{kN}-\mathrm{m}$

- Beban Pejalan kaki

$\mathrm{A}=$ Luas trotoar yang dibebani pejalan kaki (m2)

Beban hidup merata q:

Untuk $\mathrm{A}<10 \mathrm{~m} 2$

$5 \mathrm{kPa}$

Untuk $10 \mathrm{~m} 2<\mathrm{A}<100 \mathrm{~m} 2 \quad \mathrm{q}=$

$5-0.033 \times(\mathrm{A}-10) \mathrm{kPa}$

Untuk $A>100 \mathrm{~m} 2$

$2 \mathrm{kPa}$

Luas bidang trotoar yang di dukung abutmen,

$A=b_{2} \times \frac{L}{2} \times n=28 m$

Beban merata pada pedestrian, $\mathrm{q}=5-0.033 \times(\mathrm{A}-10)=4,406 \mathrm{kPa}$

Beban pada Abutmen akibat pejalan kaki

$\mathrm{P}_{\mathrm{TP}}=\mathrm{A} \times \mathrm{q}=123,368 \mathrm{kN}$

Eksentrisitas beban terhadap pondasi, $\mathrm{e}=-\frac{B_{x}}{2}+\mathrm{b}_{8}+\frac{b_{7}}{2}=0,15 \mathrm{~m}$

Momen pada pondasi akibat pejalan kaki

$\mathrm{M}_{\mathrm{TP}}=\mathrm{P}_{\mathrm{TP}} \mathrm{X} \mathrm{e}=18,5052 \mathrm{kN}-\mathrm{m}$

- Gaya Rem

Besarnya gaya rem arah memanjang jembatan tergantung dari panjang jembatan (L), sebagai berikut:

Gaya Rem TTB $=250 \mathrm{kN}$ untuk $\mathrm{Lt}<80 \mathrm{~m}$

Gaya Rem TTB $=250+2,5 *(\mathrm{Lt}-80) \mathrm{kN}$ untuk $80<\mathrm{Lt}<180 \mathrm{~m}$

Gaya Rem TTB $=500 \mathrm{kN}$ untuk $\mathrm{Lt}>180 \mathrm{~m}$

Untuk Lt $=\mathrm{L}=28,00 \mathrm{~m}$

Gaya Rem TTB $=250 \mathrm{kN}$

Lengan terhadap pondasi akibat gaya rem, $\mathrm{YTB}=9,72 \mathrm{~m}$

Momen padapondasi akibat gaya rem, $\mathrm{MTB}=2430 \mathrm{kN}-\mathrm{m}$

Lengan terhadap breast wall, Y'TB $=8,37$ 
$\mathrm{m}$

- Pengaruh Temperatur

temperatur maksimum rata-rata $\mathrm{T}$ maks $=$ $40^{\circ} \mathrm{C}$ temperatur minimum rata-rata $\mathrm{T}$ min $=15^{\circ} \mathrm{C}$

$\mathrm{dT}=(\mathrm{T}$ maks $-\mathrm{T} \min ) / 2$

Perbedaan temperatur pada slab $\mathrm{dT}=$ $12,5^{\circ} \mathrm{C}$

Koefisien muai panjang beton $\alpha=1,00 \mathrm{E}$ 05

Modulus elastisitas beton Ec $=25742,9602 \mathrm{Mpa}$

Kekakuan geser untuk tumpuan berupa elastomeric $\mathrm{k}=1500 \mathrm{kN} / \mathrm{m}$

Panjang girder $\mathrm{L}=28,00 \mathrm{~m}$

Jumlah tumpuan elastomeric (Jumlah girder)

$\mathrm{n}=7$ buah

Gaya pada abutmen akibat pengaruh temperatur

TET $=18,375 \mathrm{kN}$

Lengan terhadap pondasi YET $=2,85 \mathrm{~m}$

Momen pada pondasi $\mathrm{MET}=52,36875$

$\mathrm{kN}-\mathrm{m}$

Lengan terhadap breast wall $\mathrm{Y}^{\prime} \mathrm{ET}=1,5$ $\mathrm{m}$

$\mathrm{M}^{\prime} \mathrm{ET}=27,5625 \mathrm{kN}-\mathrm{m}$

- Beban Angin

Angin meniup samping jembatan

$\mathrm{T}_{\mathrm{EW}}=0,0006 \times \mathrm{CW} \times(\mathrm{Vw})^{2} \times \mathrm{Ab}$

Dengan: $\mathrm{C}_{\mathrm{w}}=$ Koefisien seret 1,25

$\mathrm{V}_{\mathrm{w}}=$ kecepatan angin rencana $35 \mathrm{~m} /$ det

$\mathrm{Ab}=$ luas koefisien bagian samping jembatan $\left(\mathrm{m}^{2}\right)$

$\mathrm{T}_{\mathrm{EW}}=0,0012 \times \mathrm{Cw} \times(\mathrm{Vw})^{2} \quad 1,84 \mathrm{kN} / \mathrm{m}$

Beban angin pada abutment :

$\mathrm{T}_{\mathrm{EW} 1}=0.0006 \times \mathrm{CW} \times(\mathrm{Vw})^{2} \times \mathrm{Ab}=45,02$ $\mathrm{kN}$

Lengan thd pondasi $: \mathrm{Y}_{\mathrm{EW}}=\mathrm{h} 7+\mathrm{ha} / 2=$ 4,60 m

Momen pada pondasi akibat beban angin :

$\mathrm{M}_{\mathrm{EW}}=\mathrm{T}_{\mathrm{EW} 1} \mathrm{x} \mathrm{Y}_{\mathrm{EW}}=207,09 \mathrm{kN}-\mathrm{m}$

Lengan terhadap breast wall :

$\mathrm{Y}^{\prime}{ }_{\text {EW }}=\mathrm{h} 7$ - h9-h11+ha/2 = 3,25 m

Momen pada breast wall

$\mathrm{M}_{\mathrm{EW}}^{\prime}=\mathrm{T}_{\mathrm{EW} 1 \mathrm{X}} \mathrm{Y}^{\prime}{ }_{\mathrm{EW}}=146,31 \mathrm{kN}-\mathrm{m}$

Tabel 3.5 Data gempa dari pusjatan

Angin meniup kendaraan

$\mathrm{T}_{\mathrm{EW}}=0,0012 \times \mathrm{CW} \times(\mathrm{Vw})^{2} \times \mathrm{L} / 2$
Dengan, $\mathrm{Cw}=$ Koefisien seret 1,25

$\mathrm{Vw}=$ kecepatan angin rencana $35 \mathrm{~m} /$ det

$\mathrm{T}_{\mathrm{EW}}=0,0012 \times \mathrm{CW} \times(\mathrm{Vw})^{2}=1,764 \mathrm{kN} / \mathrm{m}$

Panjang bentang $\mathrm{L}=28,00 \mathrm{~m}$

Tinggi bidang samping jembatan ha $=$ $3,50 \mathrm{~m}$

$\mathrm{Ab}=(\mathrm{L} \times \mathrm{ha}) / 2=49,00 \mathrm{~m}^{2}$

Beban angin pada abutment :

$\mathrm{T}_{\mathrm{EW} 2}=0.0012 \times \mathrm{CW} \times(\mathrm{Vw})^{2} \times \mathrm{L} / 2=$ $24,696 \mathrm{kN}$

Lengan terhadap pondasi :

$\mathrm{Y}_{\mathrm{EW}}=\mathrm{h}_{7}+\mathrm{hb}+\mathrm{ts}+\mathrm{ta}=4,65 \mathrm{~m}$

Momen pada pondasi akibat beban angin :

$\mathrm{M}_{\mathrm{EW}}=\mathrm{T}_{\mathrm{EW} 1} \times \mathrm{Y}_{\mathrm{EW}}=114,8364 \mathrm{kN}-\mathrm{m}$

Lengan terhadap breast wall :

$\mathrm{Y}^{\prime}{ }_{\mathrm{EW}}=\mathrm{h}_{7}-\mathrm{h}_{11}-\mathrm{h}_{9}=3,30 \mathrm{~m}$

Momen pada breast wall

$\mathrm{M}_{\mathrm{EW}}^{\prime}=\mathrm{T}_{\mathrm{EW} 2} \mathrm{X} \mathrm{Y}_{\mathrm{EW}}^{\prime}=81,4968 \mathrm{kN}-\mathrm{m}$

Beban angin ke lantai jembatan

Bidang vertical yang ditiup angin merupakan bidang samping kendaraan dengan tinggi 2,0 meter diatas lantai jembatan $\mathrm{h}=2,0 \mathrm{~m}$

Jarak antar roa kendaraan $\quad \mathrm{x}=1,75 \mathrm{~m}$

Transfer beban angin kelantai jembatan

$\mathrm{P}_{\mathrm{EW}}=2 \times\left(0.5 \times \frac{h}{x} \times T_{E W}\right) x\left(\frac{L}{2}\right)=\mathrm{P}_{\mathrm{EW}}=$ $28,224 \mathrm{kN}$

Eksentrisitas beban terhadap pondasi e $=$ $0,15 \mathrm{~m}$

Momen pada pondasi akibat transfer beban angin $\mathrm{M}_{\mathrm{EW}}=4,2336 \mathrm{kN}-\mathrm{m}$

- Beban Gempa

Beban gempa statik ekivalen

$\mathrm{T}=2 * \pi * \sqrt{ }(\mathrm{Wt} /(\mathrm{g} * \mathrm{Kp}))$

Beban Gempa Arah Memanjang Jembatan

(Arah-X)Tinggi Breast wall $\quad \mathrm{Lb}=$

$6,47 \mathrm{~m}$

Ukuran penampang breast wall

$\mathrm{b}=13,0 \mathrm{mh}=1,5 \mathrm{~m}$

Inertia penampang breast wall $\quad$ Ic $=$ $3,6563 \mathrm{~m}^{4}$

Mutu beton, K-361

$\mathrm{f}^{\prime} \mathrm{c}=30 \mathrm{MPa}$

Modulus elastisitas beton

$\mathrm{Ec}=25742,9602 \mathrm{MPa}$

$\mathrm{Ec}=25742960,2 \mathrm{kPa}$

Nilai Kekakuan

$\mathrm{Kp}=1042564,14$

Percepatan Gravitasi

$\mathrm{g}=9,8 \mathrm{~m} / \mathrm{det}^{2}$ 
Berat sendiri struktur atas

$\mathrm{P}_{\mathrm{MS}(\text { str atas) }}=1466,5 \mathrm{kN}$

Berat Sendiri struktur

bawahP $\mathrm{PS}_{\mathrm{MS} \text { (tr bawah) }}=7416,5395 \mathrm{kN}$

Berat sendiri total struktur

$\mathrm{W}_{\mathrm{TP}}=8149,7895 \mathrm{kN}$

Waktu getar alami struktur

$\mathrm{T}=0,1773652$ detik

Untuk Wilayah kota Malang, lebih tepatnya lokasi jembatan Sengkaling menggunakan koordinat -7.921290 LS dan 112.597403 BT.

\begin{tabular}{llll}
\hline PGA $(g)$ & 0,3 & PSA $(g)$ & 0,360 \\
\hline $\mathrm{S}_{\mathrm{S}}(\mathrm{g})$ & 0,571 & $\mathrm{~S}_{\mathrm{DS}}(\mathrm{g})$ & 0,767 \\
$\mathrm{~S}_{1}(\mathrm{~g})$ & 0,299 & $\mathrm{~T}_{0}$ (detik) & 0,141 \\
$\mathrm{SD} 1$ & 0,539 & $\mathrm{~T}_{\mathrm{S}}$ (detik) & 0,767 \\
\hline
\end{tabular}

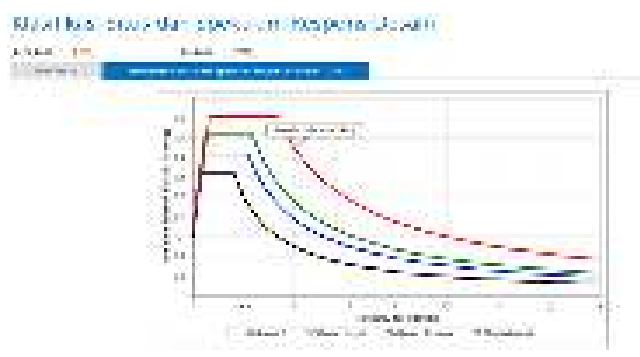

Gambar 4.15 Data Gempa dari Pusjatan Sumber: petagempa.pusjatan.pu.go.id

Tabel 3.6 Data Spektra Respon

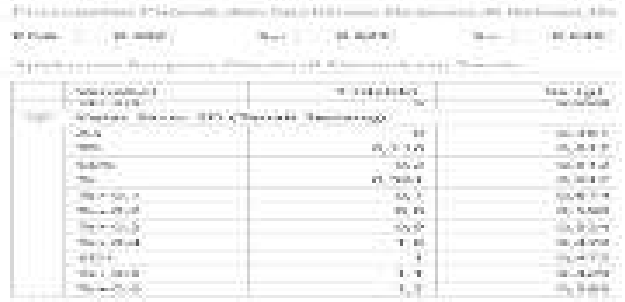

Sumber: petagempa.pusjatan.pu.go.id

$\frac{\sum t i=30}{\sum \frac{t 1}{n}=0,2+0,16+0,15+0,1}=\frac{30}{0,61}=$ $49,1 \approx 50$

Nilai rata-rata SPT adalah 50 ( Kelas situs tanah Keras)

Mencari nilai Csm untuk $\mathrm{T}>\mathrm{T} 0$

$\mathrm{Csm}=(\mathrm{SDS}-\mathrm{AS}) \mathrm{T} / \mathrm{To}+\mathrm{As}_{\mathrm{S}}$

$$
=0,388
$$

untuk struktur jembatan dengan daerah sendi plastis beton bertulang, $\mathrm{S}=1,3 \mathrm{~F} \mathrm{~S}=$ $1,0 \mathrm{~F}$

dengan, $\mathrm{F}=1,25-0,025 \times \mathrm{n}$ dan

$\mathrm{F}$ harus diambil $>1$

$\mathrm{F}=$ faktor perangkaan

$\mathrm{n}=$ jumlah sendi plastis yang menahan deformasi arah lateral

Untuk, $\mathrm{n}=1$

Maka $\mathrm{F}=1,25-0,025 \times \mathrm{n}=1,225$

Faktor tipe struktur, $\mathrm{S}=1,225$

Koefisien beban gempa horisontal,

$\mathrm{Kh}=\mathrm{C} \times \mathrm{s}=0,4753$

Untuk jembatan yang memuat $>2000$ kendaraan/hari, jembatan pada jalan raya utama atau arteri, dan jembatan dimana terdapat route alternatif.maka diambil faktor kepentingan, $\mathrm{I}=1$

Gaya gempa $\mathrm{T}_{\mathrm{EQ}}=0,4753 \mathrm{xWt}$

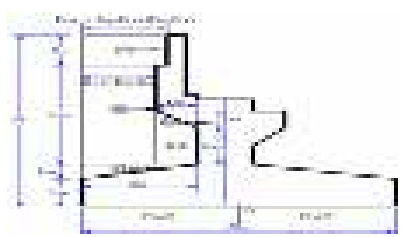

Gambar 4.16 Beban Gempa statik ekivalen Sumber: [C] 2010:MNI-BE

$$
\begin{aligned}
& \mathrm{h}_{1}=0,4 \quad \mathrm{~m} \quad \mathrm{~h}_{6}=\quad 0,5 \quad \mathrm{~m} \quad \mathrm{~h}_{11}=\quad 1
\end{aligned}
$$

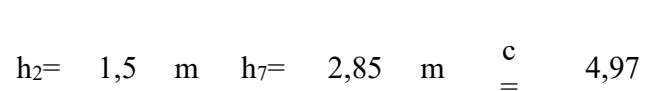

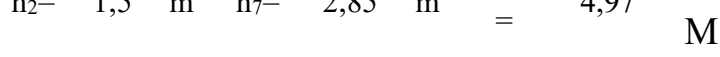

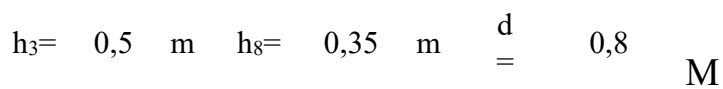

$$
\begin{aligned}
& \begin{array}{c}
\mathrm{h}_{4}- \\
=
\end{array} \quad 1 \quad \mathrm{~m} \quad \mathrm{~h}_{9}=\quad 0,35 \quad \mathrm{~m} \quad \mathrm{~h}_{13}=\quad 7,97 \quad \mathrm{M} \\
& \begin{array}{lllllllll}
\mathrm{h}_{5} & 0,5 & \mathrm{~m} & \mathrm{~h}_{10}= & 1 & \mathrm{~m} & \begin{array}{l}
\mathrm{h} \\
=
\end{array} & 9,72 & \mathrm{M}
\end{array}
\end{aligned}
$$

Beban Gempa Arah Melintang Jembatan (Arah Y)

Tinggi Breast wall $\mathrm{Lb}=6,47 \mathrm{~m}$

Ukuran penampang breast wall $b=13,0$ $\mathrm{m}$

$\mathrm{h}=1,5 \mathrm{~m}$

Inertia penampang breast wallIc $=3,6563$ $\mathrm{m}^{4}$ 
Mutu beton, K-361 $\mathrm{f}^{\prime} \mathrm{c}=30 \mathrm{MPa}$

Modulus elastisitas beton

$\mathrm{Ec}=25742,96 \mathrm{MPa}$

$\mathrm{Ec}=25742960,20 \mathrm{kPa}$

Nilai Kekakuan Kp $=1042564,14$

Percepatan Gravitasi g = 9,8 m/det ${ }^{2}$

Berat sendiri struktur atas $\quad \mathrm{P}_{\mathrm{MS}(\mathrm{str} \text { atas) }}=$ $1466,50 \mathrm{kN}$

Berat Sendiri struktur bawah $\mathrm{P}_{\mathrm{MS}(\text { str bawah })}=$ $7416,54 \mathrm{kN}$

Berat sendiri total struktur $\mathrm{W}_{\mathrm{TP}}=$ $8149,7895 \mathrm{kN}$

Waktu getar alami struktur $\mathrm{T}=$

0,1773652 detik

Kondisi tanah dasar termasuk $=$ Tanah Sedang lokasi wilayah gempa 2

Kondisi tanah dasar termasuk $=$ Tanah

Sedang lokasi gempa Malang.

Faktor modifikasi respon untuk bangunan bawah

$\mathrm{R}=1,5$

Mencari nilai Csm untuk T $>$ T0

$\mathrm{Csm}=(\mathrm{SDS}-\mathrm{AS}) \mathrm{T} / \mathrm{To}+\mathrm{As}_{\mathrm{s}}$ $=0,388$

untuk struktur jembatan dengan daerah sendi plastis beton bertulang,

$\mathrm{S}=1,3 \mathrm{~F} \mathrm{~S}=1,0 \mathrm{~F}$

dengan, $\mathrm{F}=1,25-0,025 \times \mathrm{n}$ dan $\mathrm{F}$ harus

diambil $>1$

$\mathrm{F}=$ faktor perangkaan

$\mathrm{n}=$ jumlah sendi plastis yang menahan deformasi arah lateral

Untuk, $\mathrm{n}=1$ maka $\mathrm{F}=1,25-0,025 \times \mathrm{n}$ $=1,225$

Faktor tipe struktur, $\mathrm{S}=1,225$

Koefisien beban gempa horisontal,

$\mathrm{Kh}=\mathrm{C} / \mathrm{R} \times \mathrm{S} \quad=0,4119$

Untuk jembatan yang memuat $>2000$ kendaraan/hari, jembatan pada jalan raya utama atau arteri, dan jembatan dimana terdapat route alternatif.maka diambil faktor kepentingan,

$\mathrm{I}=1$

Gaya Gempa

$\mathrm{T}_{\mathrm{EQ}}=0,4119 \mathrm{x} \mathrm{Wt}$

$\mathrm{P}_{\mathrm{MA}}=579,600 \mathrm{kN}$

$\mathrm{Wt}=9462,640 \mathrm{kN}$

Beban gempa arah melintang jembatan

$\mathrm{T}_{\mathrm{EQ}}=3897,914 \mathrm{kN}$
Momen pada pondasi akibat beban gempa $\mathrm{M}_{\mathrm{EQ}}=\mathrm{T}_{\mathrm{EQ}} \times \mathrm{Y}_{\mathrm{EQ}}=21055,010 \mathrm{kN}-\mathrm{m}$

Tekanan Tanah Dinamis Akibat Beban Gempa

Gaya gempanarah lateral akibat tekanan tanah dinamis dihitung dengan menggunakan koifisien tekanan tanah dinamis $(\triangle \mathrm{KaG})$ sebagai berikut:

$\theta=\tan -1(\mathrm{Kh})$

$\mathrm{KaG}=\cos 2\left(\varphi^{\prime}-\theta\right) /\left[\cos 2 \theta\left\{1+\sqrt{ }\left(\sin \left(\varphi^{\prime}-\right.\right.\right.\right.$ $\theta)) / \cos \theta\}]$

$\Delta \mathrm{kaG}=\mathrm{KaG}-\mathrm{Ka}$

Tekanan tanah dinamis $\mathrm{p}=\mathrm{H}^{*} \mathrm{ws} * \Delta \mathrm{kaG}$ $\mathrm{kN} / \mathrm{m} 2$

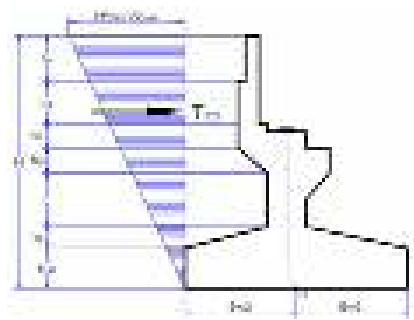

Gambar 4.17 Tekanan tanah dinamis akibat beban gempa

Sumber: [C] 2010:MNI-BE

$\mathrm{H}=9,72 \mathrm{~m}$

$\mathrm{By}=13,0 \mathrm{~m}$

$\mathrm{Kh}=0,41193$

$\varphi^{\prime}=1,00250 \mathrm{rad}$

$\mathrm{Ka}=0,085343$

$\mathrm{Ws}=17,2 \mathrm{kN} / \mathrm{m} 3$

$\theta=0,39074552 \mathrm{rad}$

$\cos 2\left(\varphi^{\prime}-\theta\right) \quad=0,6701721$

$\left[\cos 2 \theta\left\{1+\frac{\sqrt{\sin \varphi 1-\theta}}{\cos \theta}\right\}\right]=1,498220$

$\mathrm{KaG}=0,44731233$

$\Delta \mathrm{KaG}=0,36196908$

Gaya gempa lateral $\mathrm{TEQ}=1 / 28 \mathrm{H}^{2} \mathrm{x}$ ws $\mathrm{x}$ $\Delta \mathrm{k}_{\mathrm{aG}} \mathrm{x}$ By $=3823,365 \mathrm{kN}$

Lengan terhadap pondasi $\mathrm{y}_{\mathrm{EQ}}=2 / 3 \times \mathrm{H}=$ $6,5 \mathrm{~m}$

Momen akibat b. gempa $\mathrm{M}_{\mathrm{EQ}}=24775,408$ $\mathrm{kN}-\mathrm{m}$

- Gesekan Pada Perletakan (FB)

Koifisien geser tumpuan elastomer, $\mu=$ 0.18

Gaya gesek yang timbul hanya ditinjau terhadap beban berat sendiri dan beban mati tambahan 


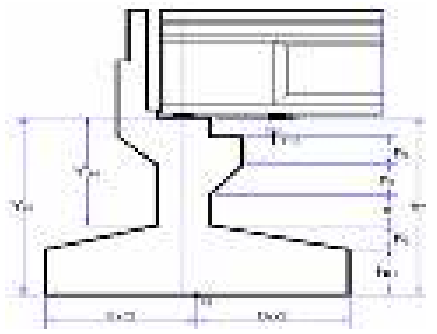

Gambar 4.18 Gesekan pada perletakan (FB)

Sumber: [C] 2010:MNI-BE

Kombinasi Beban Kerja

Reaksi abutmen akibat:

Berat sendiri struktur

atas:

$\mathrm{P}_{\mathrm{MS}}=\quad 1466,5 \quad \mathrm{kN}$

Beban mati tambahan,

$$
\mathrm{P}_{\mathrm{MA}}=\quad 579,600 \mathrm{kN}
$$

Reaksi abutmen akibat beban tetap:

$$
\mathrm{P}_{\mathrm{T}}=
$$

$2046,100 \mathrm{kN}$

Gaya gesek pada perletakaan

$\mathrm{T}_{\mathrm{FB}}=$

$368,298 \quad \mathrm{kN}$

Lengan terhadap pondasi

$$
\mathrm{y}_{\mathrm{FB}}=\quad 2,85 \quad \mathrm{M}
$$

Momen pada pondasi akibat gempa,

$\mathrm{M}_{\mathrm{FB}}=$

1049,649

$\mathrm{kN}-$

$\mathrm{m}$

Lengan terhadap breast wall

$$
\mathrm{y}^{\prime}{ }_{\mathrm{FB}}=
$$

\begin{tabular}{|c|c|c|c|c|c|c|c|}
\hline \multicolumn{2}{|r|}{ mestmosinga } & \multirow{2}{*}{ 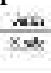 } & \multirow{2}{*}{$\frac{7 \times a}{?}$} & \multicolumn{2}{|c|}{ There } & \multicolumn{2}{|c|}{360} \\
\hline$\%$ & $8 x+3+\pi$ & & & 3 & 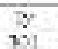 & 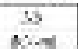 & 26 \\
\hline a. & Solisy & & & & & & \\
\hline & Indenimi & is & $6.8 \mathrm{~s}$ & & & Waiz & \\
\hline & Dosrnt: $=$ hr. & m & 130 & & & 18.4 & \\
\hline & lifinelad & $\mathrm{a}$ & & 12111 & & 30150 & \\
\hline & molitic & & & & & & \\
\hline & Dusarles F & $D$ & IISA: & & & HES & \\
\hline & Dozrgubaters & II & $1 \%$ & & & $1 ! 21$ & \\
\hline & netw & & & $x-2$ & & प. & \\
\hline & Aimiune & & & & & & \\
\hline & $\pi \operatorname{tinses}$ & $\pi$ & & Ba & & !? & \\
\hline & Dorsta & $5 \%$ & 네: & & का & 포 & $2 ! x$ \\
\hline & mats? & k. & & $=2$ & -arus & 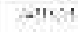 & "Ir:ai \\
\hline & phasirn & & & $.5 \cdot .4$ & & Alistst & \\
\hline & sibies & & & & & & \\
\hline & 100 & 78 & & काa & & पक्ष & \\
\hline
\end{tabular}

Momen pada breast wall

$\mathrm{M}_{\mathrm{FB}}^{\prime}=$

$552,447 \quad \mathrm{~m}$

Tabel 3.7 Rekap Beban Kerja

\begin{tabular}{|c|c|c|c|c|c|c|c|}
\hline \multicolumn{2}{|r|}{ beiose? } & $2 \pi$ & T) 186 & \multicolumn{2}{|c|}{ llemal } & \multicolumn{2}{|c|}{ inea } \\
\hline $\bar{x}$ & it ats & $5=$ & $\omega$ & s & w5 & $\because \theta$ & Mes \\
\hline$\Sigma$ & $2 \cdots$ & & & & & & \\
\hline & ifmerisidi & 96 & 60 & & & $\operatorname{tin}=3$ & \\
\hline & rote. $\quad 10$ & $\mathrm{~m}$ & $\mathrm{YN}$ & & & as & \\
\hline & 2010eated & $\mathrm{Th}$. & & 2.29 & & Hर八: : & \\
\hline 1 & buts $=\pi n$ & & & & & & \\
\hline & trowes: 5 & $\pi$ & 626 & & & $1 \%: x$ & \\
\hline & futs mais is & 2 & iat. & & & :us & \\
\hline & "xund & $D$ & & צxi & & $34: 200$ & \\
\hline & tixgertz & $\pi$ & & $28 x$ & & 던 & \\
\hline & $x+2 x$ & the & $=$ & & 7.4 & 17. & \pm 5 \\
\hline & Thtepits & & & & & & \\
\hline & $9 x-i n=0$ & & & & & & \\
\hline 5 & Treisen & & & & & & \\
\hline & $10 \mathrm{wa}=$ & +4 & & $6<5$ & & 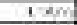 & \\
\hline
\end{tabular}

Tabel 3.8 Daya Layan 1

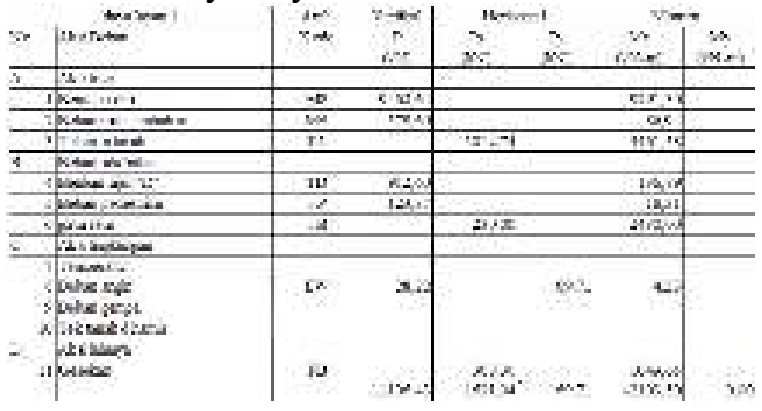

Tabel 3.9 Daya Layan 2

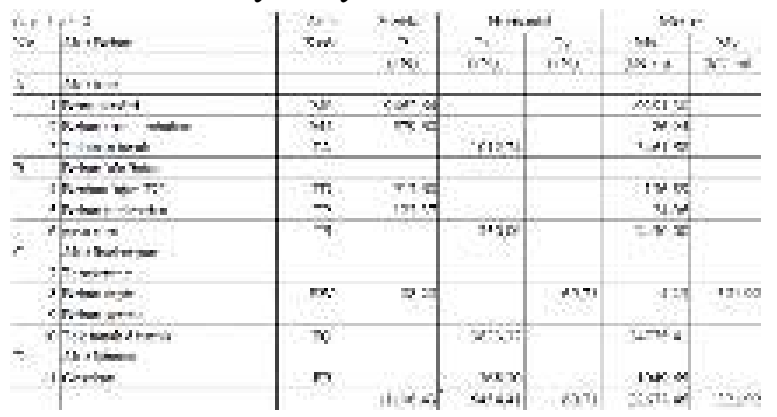

Tabel 3.10 Daya Layan 3

Tabel 3.11 Daya Layan 4

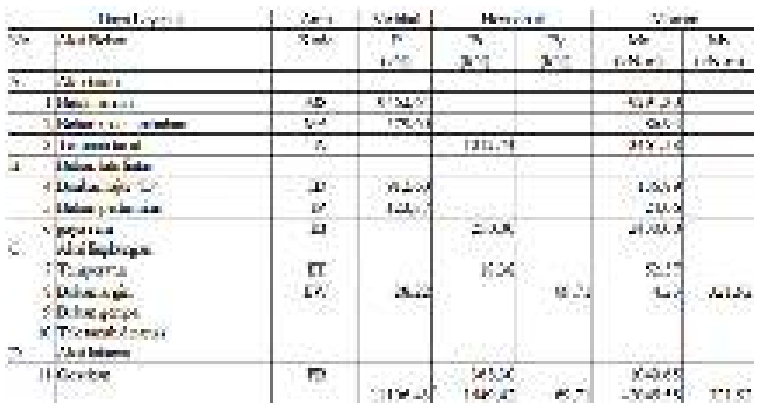


Tabel 3.12 Ekstrim 1

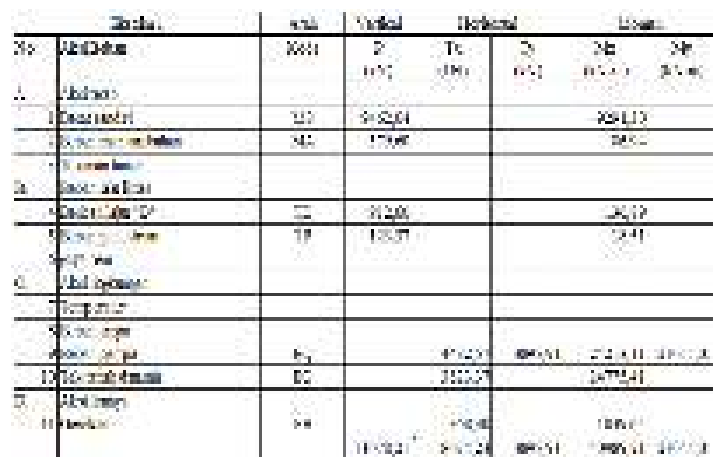

Kontrol Stabilitas Guling

Stabilitas guling arah $\mathrm{X}$

Pondasi tiang tidak diperhitungkan dalam analisis stabilitas terhadap guling, sehingga $\mathrm{SF}=2,2$

Letak titik guling A (Ujung Pondasi)

Terhadap pusat Pondasi :

$\frac{B_{x}}{2}=2,75 \mathrm{~m}$

$\mathrm{k}=$ persen kelebihan beban yang diijinkan $(\%)$

$\mathrm{Mx}=$ momen penyebab guling arah $\mathrm{X}$

Momen penahan guling : $\mathrm{MPx}=$ $P \times\left(\frac{B x}{2}\right) \times(1+k)$ Angka aman terhadap guling:

$\mathrm{SF}=\mathrm{MPx} / \mathrm{Mx}$ harus $\geq 2,2$

\begin{tabular}{|c|c|c|c|c|c|c|c|}
\hline \multirow{2}{*}{3} & \multirow{2}{*}{ k:4roses at:3 } & \multirow[t]{2}{*}{1} & F & $\%$ & wh & \multirow[t]{2}{*}{$\mathrm{t}$} & \multirow{2}{*}{ inery } \\
\hline & & & $\therefore$ & $2 i n$ & tis & & \\
\hline & $a^{2}+s^{2}+42$ & 34 & $1: 1.5=$ & \multicolumn{2}{|c|}{$20: 462005$} & \multicolumn{2}{|c|}{$\therefore 4$-g.kia } \\
\hline & Hit4Litasin & $3 i$ & $1 . .6 .1$ & \multicolumn{2}{|c|}{$x-203: 465$} & \multicolumn{2}{|c|}{$1: 12, \mathrm{k}: \mathrm{z}$} \\
\hline & Gistatisas & $x_{0}$ & $1.16 i$ & \multicolumn{2}{|c|}{$x-x: 10 x:<b^{4}$} & 4.4 & Sik is \\
\hline & $2 x^{2}+1 v_{4}=1$ & $x_{i}$ & 1.15 & \multicolumn{2}{|c|}{$x-5,8 \times 205$} & \multirow{2}{*}{ 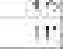 } & a:x: $: 0$ \\
\hline & $=5-20$ & $y_{i}$ & $\cos$ & sed & $402 x$ & & d:N:a \\
\hline
\end{tabular}

Nilai SF pada daya layan 1, daya layan 3 dan daya layan 4 bernilai negatif, jadi nilai tersebut di absolutkan.

\begin{tabular}{|c|c|c|c|c|c|}
\hline$x$, & 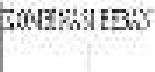 & 1 & ? & $\begin{array}{l}\mathrm{N} . \\
\mathrm{N}\end{array}$ & We:ses \\
\hline & AHAdTS: & & $1 \ldots x t$ & - ll & $4 S Y 2 x=1$ \\
\hline & $-4: 22.5=$ & 8 & 1.2.6t & 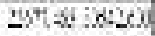 & 1802030 \\
\hline & Aindis-j & is & $1 \leqslant 04$ & $\angle 46 x=\alpha+3 e 0$ & 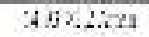 \\
\hline & 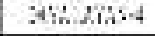 & 18 & Troat & $2405 x \cdot 6+200$ & $48 x 2.27$ \\
\hline & 3534 & 34 & triz: & 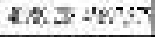 & $11192 \times 20$ \\
\hline
\end{tabular}

Stabilitas Guling arah Y

Letak titik guling A (Ujung Pondasi) terhadap pusat pondosi

$\mathrm{By} / 2=6,5 \mathrm{~m}$

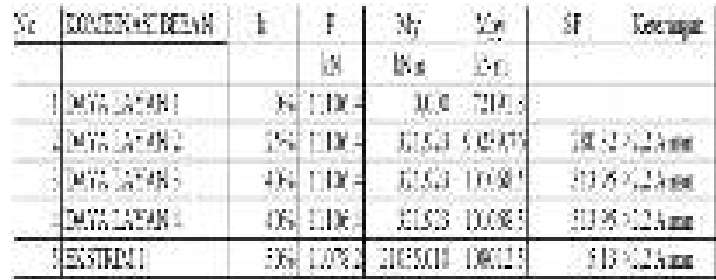

\section{Kontrol Stabilitas Geser}

Stabilitas geser arah X

Parameter pile cap :

Sudut gesek dalam $\varphi=20^{\circ}$

Kohesi $\quad \mathrm{c}=5,7 \mathrm{kPa}$

Ukuran pile cap $\mathrm{Bx}=5,5 \mathrm{~m}$

$$
B y=13,0 \mathrm{~m}
$$

$\mathrm{k}=$ persen kelebihan beban yang diijinkan $(\%)$

$\mathrm{Tx}=$ gaya penyebab geser

Gaya penahan geser :

$\mathrm{H}=(\mathrm{c} * \mathrm{Bx} * \mathrm{By}+\mathrm{P} * \tan \varphi) *(1+\mathrm{k})$ harus $>1.1$

\begin{tabular}{|c|c|c|c|c|c|c|c|}
\hline \multicolumn{3}{|c|}{\begin{tabular}{l|l} 
No & KOMBINASI BEBAN \\
\end{tabular}} & Tx & P & $\mathrm{H}$ & SF & Keterangan \\
\hline & Daya layan 1 & & 1631,04 & 11106,4315 & 4450,403 & 2,729 & $>1,1$ Aman \\
\hline & Daya layan 2 & & 5454,41 & 11106,4315 & 4450,403 & 0,816 & $<1,1 \mathrm{~N}_{0} \mathrm{G}_{0}$ \\
\hline & Daya Layan 3 & & 1649,42 & 11106,4315 & 4450,403 & 2,698 & $>1,1$ Aman \\
\hline & Daya layan 4 & & 1649,42 & 11106,4315 & 4450,403 & 2,698 & $>1,1$ Aman \\
\hline & ekstrim 1 & & 8674,24 & 11078,2075 & 6456,419 & 1,116 & $>1,1$ Aman \\
\hline
\end{tabular}

Stabilitas Geser Arah Y

Parameter pile cap :

Sudut gesek dalam $\varphi=20^{\circ}$

Kohesi $\quad \mathrm{c}=5,7 \mathrm{kPa}$

Ukuran pile cap $\mathrm{Bx}=5,5 \mathrm{~m}$

$\mathrm{By}=13,0 \mathrm{~m}$

$\mathrm{k}=$ persen kelebihan beban yang diijinkan $(\%)$

$\mathrm{Tx}=$ gaya penyebab geser

Gaya penahan geser :

$\mathrm{H}=(\mathrm{c} * \mathrm{Bx} * \mathrm{By}+\mathrm{P} * \tan \varphi) *(1+\mathrm{k})$ harus $>1.1$

\begin{tabular}{|c|c|c|c|c|c|c|c|}
\hline No & KOMBINASI BEBAN & $\mathrm{k}$ & Ty & $\bar{P}$ & $\mathrm{H}$ & SF & Keterangan \\
\hline & & & $\mathrm{kN}$ & $\mathrm{kN}$ & $\mathrm{kN}$ & & \\
\hline & DAYA LAYAN 1 & $0 \%$ & \begin{tabular}{ll|}
69,7148 \\
\end{tabular} & \begin{tabular}{|l|}
11106,4315 \\
\end{tabular} & 4450,403 & 63,84 & $>1,1$ Aman \\
\hline & 2 DAYA LAYAN 2 & $25 \%$ & 69,7148 & \begin{tabular}{|l|}
11106,4315 \\
\end{tabular} & 5461,117 & 78,34 & $>1,1$ Aman \\
\hline & 3 DAYA LAYAN 3 & $40 \%$ & 69,7148 & \begin{tabular}{|l|}
11106,4315 \\
\end{tabular} & 6067,545 & 87,03 & $>1,1$ Aman \\
\hline & 4 DAYA LAYAN 4 & $40 \%$ & 69,7148 & \begin{tabular}{|l|}
11106,4315 \\
\end{tabular} & 6067,545 & 87,03 & $>1,1$ Aman \\
\hline & 5 EKSTRIM 1 & $50 \%$ & 3897,91 & 11078,2075 & 6456,419 & 1,66 & $>1,1$ Aman \\
\hline
\end{tabular}

\section{Pembahasan}

Berdasarkan analisa kapasitas abutmen dengan beban gempa pada jembatan Taman Rekreasi Sengkaling Malang. Di dapatkan beberapa analisa sebagai berikut:

1. Menurut SNI 2833:2016 Kelas situs pada lokasi yang di tinjau merupakan Tanah 
sangat padat atau keras karena nilai hasil uji penetrasi standar tanah adalah 50

$$
\begin{gathered}
\frac{\sum t i}{\sum t i / n}=\frac{30}{0,2+0,16+0,15+0,1}=\frac{30}{0,61} \\
=49,1 \approx 50
\end{gathered}
$$

2. Untuk Stabilitas Guling arah $X$

Pada kombinasi beban nilai SF kurang dari 2,2 dan nilai kombinasi beban daya layan 1,3 dan 4 bernilai negatif (-) yaitu daya layan 1 sebesar -14,52 menjadi 14,52 dan untuk daya layan 3,4 sebesar $-14,93$ menjadi 14,93 nilai-nilai tersebut di absolutkan karena ketinngian abutmen kurang.

3. Untuk Stabilitas geser arah $\mathrm{X}$

Pada kombinasi beban daya layan 2 tersebut tidak aman karena tekanan tanah mengalami geser dengan nilai SF 0,816 < dari 1,1 agar di katakana aman. Jika terjadi gempa akan geser karena ketinggian abutmen kurang bisa menopang jembatan.

\section{KESIMPULAN}

Berdasarkan analisa kapasitas abutmen dengan beban gempa pada jembatan Taman Rekreasi Sengkaling Malang. Di dapatkan beberapa analisa sebagai berikut:

- Kapasitas abutmen pada jembatan sengkaling jika terjadi gempa mengalami guling dalam arti stabilitas geser dan guling abutmen tidak memenuhi standart dari pembebanan jembatan.

- Menurut SNI 2833:2016 Kelas situs pada lokasi yang di tinjau merupakan Tanah sangat padat karena nilai hasil uji penetrasi standar tanah adalah 50

$$
\begin{aligned}
\frac{\sum t i}{\sum t i / n}=\frac{30}{0,2+0,16+0,15+0,1} & \\
= & \frac{30}{0,61}=49,1 \approx 50
\end{aligned}
$$

- Untuk Stabilitas Guling arah X Pada kombinasi beban nilai SF kurang dari 2,2 dan nilai kombinasi beban daya layan 1,3 dan 4 bernilai negatif (-) yaitu daya layan 1 sebesar -14,52 dan untuk daya layan 3,4 sebesar -14,93 nilai-nilai tersebut di absolutkan karena ketinngian abutmen kurang. Sehingga abutmen perlu ditinjau kembali.

- Untuk Stabilitas geser arah X

Pada kombinasi beban daya layan 2 tersebut tidak aman karena tekanan tanah mengalami geser dengan nilai SF 0,816 $<$ dari 1,1 agar di katakana aman. Jika terjadi gempa akan geser karena ketinggian abutmen kurang bias menopang jembatan.

\section{REFERENSI}

[1] Das, Braja M. 2006, "Principles of Geotechnical Engginering 7rd". USA: PWS Publishers.

[2] SNI 2833-2016.Perencanaan Jembatan Terhadap Beban Gempa.Badan Standarisasi Nasional. Bandung:

[3] SNI 1725-2016. Pembebanan untuk Jembatan.Badan Standarisasi Nasional. Bandung:

[4] Peta Gempa. http://www.petagempa.pusjatan.pu.go.i dkementrian Pekerjaan Umum.

[5] 2010:MNI-BE. "Analisis Beban Abutment". Yogyakarta:

[6] Widyaningrum, A., Indriyati, E.W., HArdini. P. 2016 "Pengaruh Perubahan Pembebanan dan Beban Gempa Terhadap Kinerja Jembatan Sungai Serayu Patikraja Banyumas". Purbalingga: Universitas Jendral Soedirman.

[7] Ardiani, K., Harry, M. 2015. Program Analisa Stabilitas Abutment.Bandung:

[8] Bowles, Joseph E. 1991. Analisa dan Desain Pondas", jilid 1,Jakarta: Erlangga.

[9] Bowles, Joseph E. 1991. "Analisa dan Desain Pondasi", jilid 2,Jakarta: Erlangga.

[10] Tandra, D., Warman. H., Farni, I. "Perencanaan Abutmen Struktur Bawah Jembatan Purus". Padang: Universitas Bung Hatta. 
Telford, Thomas. 2000. "Ice Manual of Bridge Engineering”. London: 1 Heron Quay Publiher. 